\title{
The Impact of Sheltered Instruction Observation Protocol Model on Student Teachers' Teaching Skills and Self-efficacy
}

\author{
Aly A. Koura \\ Faculty of Education, Mansoura University, Egypt \\ Faten A. Zahran \\ The Higher Institute of Languages, Mansoura, Egypt
}

\begin{abstract}
The main purpose of this study was to determine the impact of sheltered instruction observation protocol on student teachers' teaching skills and self-efficacy. Questions formulated to achieve the purpose of the study focused on. (1) Determining the teaching skills necessary for the EFL student teachers. (2) Finding out differences in both EFL student teachers' teaching performance observation checklist experimental and control group. (3) Finding out differences in both EFL student teachers' self-efficacy scale of experimental and control group. Twenty two EFL student teachers constituted the sample for this study and two instrumentsdesigned by the researchers- were used for data collection. Results indicated that students of experimental group outperformed their counterparts of control group in EFL teaching performance. The effect of sheltered instruction observation protocol model on student teachers teaching skills and self-efficacy was profound and significant. Sheltered instruction observation protocol model was very motivating for student teachers and gave them opportunities to make decisions and be creative.
\end{abstract}

Index Terms - sheltered instruction, teaching skills, self-efficacy

\section{INTRODUCTION}

Teachers are the base of educational reform as well as they are the key to better quality education (Suwandee, 1995). According to Tucker, Strong and Gareis (2002), the teachers are the main key for learners' achievement. However, there is no agreement concerning the factors that make teaching qualified, proficient and effective. Consequently, the leading aim of research in field of the language teaching address the features of effective teaching in addition to the methods of incorporating these features into teachers training programs (Birjandi and Bagherkazemi, 2010). According to Evans (2008), specialized development of teachers is a necessity to serve the society and to achieve the required development according to the needs of society. On the other hand, the visions and opinions of teachers towards teaching professional development are not investigated (Swann et al., 2010). Gordon (2008) believed that the process of evaluating teachers training programs is a part of developing these programs. According to Brophy (2004) assured that constructing inspiring and encouraging learning atmosphere contribute to better quality teaching inside schoolrooms (as cited in Adel, Zareian, \& Mardekhoda, 2015).

Teachers' performances affect the development of methodology and teaching instructions particularly EFL (English as a foreign language) teachers who have to meet the standards of English as an international language (Kumaravadivelu, 2003). Teaching facilitates learning. It is the process through which a learner gets to interact with a teacher in order to gain new skills, knowledge, attitudes and opinions. As there is a general agreement that the quality of teacher and especially the foreign language teacher is one of the most important factors in the educational process that affects students' achievement, the education reform and development movement has shifted its attention to the teacher (Al-Mutawa, 2004 and Coulter, 2007). Gohar (2014) illustrated that teachers have to serve some functions inside the classroom as: organizing material, setting goals, creating encouraging atmosphere, teaching new learners in the workgroup, relating tasks to students' own experiences, motivating students and evaluating their performance. Hassan (2014) assured that an effective teacher should have clear and specific structure of instruction and evaluation, knowledge of subject matter, a scheme that permits students to state their needs, provide a safe classroom environment and give appropriate feedback to students regarding the success of their performance. English language learners (ELLs) at all levels accomplish the required tasks when provided with clear and direct instruction from their teachers. One strategy a teacher can apply for direct instructions inside classroom is to have visible language and content objectives for each lesson. Content objectives are what the students expect to know whereas language objectives are how students show they know the content (Echevarria et al., 2011).

Sheltered instruction observation protocol (SIOP) is an approach that enables to English language learners to comprehend academic subject while gaining English language proficiency. Sheltered instruction (SI) offers a structure for making academic material understandable and increasing the academic English language skills of learners through 
teaching. SI model integrates traits of operational teaching for learners (e.g., cooperative learning, reading strategies, differentiated instruction and the incorporation of the four language skills). Moreover, it contains traits specially planned to support the academic achievement of students (e.g., the insertion of language goals in the course, the progress and application of prior knowledge, and using teaching techniques to develop intellectual capacity) (Echevarria and Short, 2004). Friend et al. (2009) assured that language skills are developed through collaboration and interaction, which can be willingly made in all subject areas. Teachers train students to build meaning from texts and to comprehend content material by clear and direct instruction.

The basic steps to support English language students' academic and English language acquisition are placed in sheltered instruction procedures. For ELLs, SI is a procedure of language training that emphases content material teaching and language learning. SI is mainly useful to teachers who deal with different background and proficiency level students (Echevarria et al., 2011; Friend et al., 2009 and O’Neal et al., 2009). Sheltered instruction is recommended for any program where students are learning content through a nonnative language (Batt, 2010).

\section{A. The Context of the Problem}

In spite of the efforts of Egyptian faculties of education in providing student-teachers with the required teaching skills besides the efforts of Ministry of Education in organizing training programs for teachers, implementing new teaching techniques is a prerequisite as a result of rapid changes nowadays. Moreover, a number of supervisors noted that teachers do not apply or even follow up the current teaching strategies which in turn affect their performance negatively inside schoolrooms.

The challenges of the teaching profession are on the rise. The range and type of information that students need to know far exceed that of previous decades. In addition, the academic expectation for all students are increasing enormously. Thus, caring and competent teachers who master the teaching skills are vital to the success of the educational process. A number of studies (e.g., Koura (2002), Al-Sheikh (2004), Gohar (2014) and Hassan (2014)) assure the impact of classroom teaching performance on the achievement of their students. They reached the same conclusion that among the multiple factors that affect students' achievement is teacher effectiveness. Thus, the challenge remains to improve and promote the effectiveness of teachers in an effort to increase students' academic achievement.

\section{B. Statement of the Problem}

The problem of this study is that in spite of the stressed importance of teaching skills, student teachers lack many of the EFL teaching skills which may have a negative impact on their teaching performance that in turn affects their teaching self-efficacy.

\section{Questions}

The problem of this study can be addressed in the following questions:

1. What are the teaching skills necessary for EFL student teachers?

2. What is the effect of using SIOP model on developing EFL student teachers' teaching skills?

3. What is the effect of using SIOP model in developing EFL student teachers' self-efficacy?

\section{Significance}

The study gains its significance from the following:

1. Helping student teachers to monitor and evaluate their own teaching.

2. Providing EFL teachers with a model that may develop students' achievement.

3. Helping English curricula developers to pay attention to sheltered instruction.

\section{E. Hypotheses}

1. There is statistically significant difference between the mean score of the experimental group and the control group on the teaching skills post-observation favouring the experimental one.

2. There is statistically significant difference between the mean score of the experimental group on the teaching skills pre- and post-observation favouring the post-observation scores.

3. There is statistically significant difference between the mean score of experimental group and the control group on the post administration of self-efficacy scale favouring the experimental one.

4. There is statistically significant difference between the mean score of the experimental group on the pre and post administration of self-efficacy scale favouring the post scale scores.

\section{F. Delimitations}

The study is delimited to:

1. A sample of EFL student teachers' at faculty of education, Mansoura University.

2. A sample of lessons from Hello! English for preparatory schools, year two.

\section{G. Definitions of Terms}

Crawford, Schmeister and Biggs (2008) define SIOP model as a scheme of teaching English language that 
depends on using supporting materials, visual aids, grouping and meaningful tasks that aim at developing the language and teaching the content material to enhance learners listening, reading, speaking and writing skills.

SIOP model is operationally defined as an approach that offers a system for lesson planning and delivery that incorporates best practices for teaching English and improving student achievement.

Caprara et al., (2003) define teacher self-efficacy as a concept that affects learners' performance and leads to increased job satisfaction, commitment to teaching, greater levels of planning and organization and working longer with students who are struggling.

Teaching self-efficacy is operationally defined as one's beliefs in his/her abilities to accomplish teaching confidently and influence outcomes in the classroom and it is measured by the score that the student teachers gets on the post administration of teaching self-efficacy scale.

\section{REVIEW OF LITERATURE}

\section{A. Strategies for Improving Teaching Skills}

Research proved that SI and proficient development of teaching skills should be the main concern in facing the difficulties of working with ELL learners. SIOP is an instructional model that aids ELL students to acquire the academic material by integrating procedures and approaches that support the English language acquisition as well. Hansen- Thomas (2008) pinpointed the aim of SI, which is to offer effective and stimulating material that English native speakers trained on. SI mainly concentrates on: supportive learning, academic vocabulary, students' background in lessons, and hands-on activities. Curtin (2005) observes how students perceive SI. The results indicates that students were satisfied as they confirmed that teachers supported them with clear and direct step by step instruction based on SIOP model. Baik and Greig (2009) indicated the privileges of using SIOP model with students who are at-risk in an undergraduate program. Using the model, the researchers provided students with activities and tasks that enabled them to develop their English language. Baik and Greig's study proposed that SI programs help students increase their language skills. There was a positive relation between attendance and academic results, and the researchers assured the significance of early classification of low level learners (as cited in Todd, Stinson, \& Sivakumaran, 2011). The SIOP considered as a training model and evaluating tool for teachers. A number of researches (e.g., Gibbons, 2003 and Giouroukakis et al., 2011) noted that the increase use of SI came as a result of using assessment rubrics and observation checklist that are included in the model.

\section{B. Sheltered Instruction Observation Protocol Model (SIOP)}

SIOP was established to support lecturers with beneficial model of teaching. SI is a representation of effective teacher performance that takes into consideration the students' academic level differences (Crawford, Schmeister, and Biggs, 2008). It is through a cyclic procedure where teachers examine, use and remodel, S1OP model was designed and enhanced. SIOP model originally was an observation tool that measure teachers' performance according to the features of sheltered instruction (Echevarria and Short, 2004). Fig.1 below shows the improvement of the model.

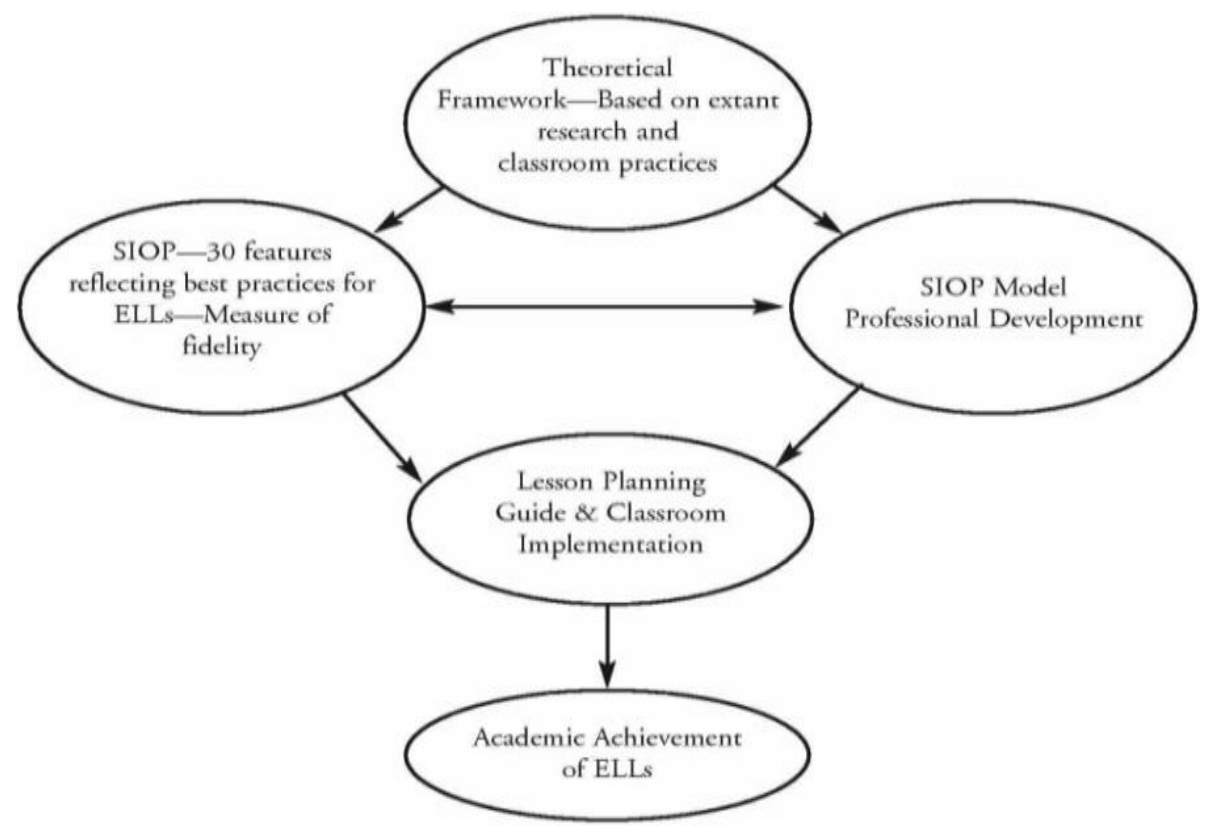

Figure 1. SIOP Model for English-Language Learners (Echevarria, 2006, p.200).

The model is a structure that guarantees that operational techniques are implemented and evaluated. SIOP model 
facilitates reflection and self- evaluation about teaching (Echevarria, 2007 and 2008). It includes the following eight components as explained by Echevarria, Vogt and Short (2008):

1. Lesson Preparation: Well-organized instructions should contain content besides language objectives. Supplementary materials for instance visual aid, diagrams, images and demonstrations should be used. These objectives include the four language modalities: reading, writing, listening, and speaking.

2. Building Background: Research proved the relation between vocabulary learning and achievement. Consequently, vocabulary teaching should be linked to learners' background.

3. Comprehensible Input: The language of instruction used by teachers should be suitable to learners' proficiency level.

4. Strategies: Learning schemes that aim at developing learners' intellectual capacity should contain meta-cognitive, intellectual, and social approaches.

5. Interaction: Learning process in which learners participate is more effective and positively beneficial.

6. Practice and Application: Involving learners in tasks and practical activities enable them to connect theoretical knowledge with the actual and practical use of this knowledge.

7. Lesson Delivery: To ensure the comprehension of the subject content, language objective should be suitable to learners' skills.

8. Review and Assessment: Effective evaluation is the base of deciding whether to continue or to give additional training.

\section{SIOP Model and Effective Instruction}

Teacher effectiveness relies on sufficient and successful training and professional development in teacher preparation programs (de Jong, 2005; Friend et al., 2009). A number of these programs depend on including language education to syllabus (Ladson- Billings, 2001). Yet, most teachers do not get the proper training that is required to work successfully with ELLs. Through interviews with teachers concerning professional development, Crawford et al. (2008) confirmed that they expressed their need to develop their performance. Likewise, in their study, Friend et al. (2009) stated that teachers had the desire to learn and apply effective approaches. Moreover, they were against teaching EFL students by teachers who are not EFL trained. Similarly, Giouroukakis et al. (2011) through a study with a big number of ELL people assured that teachers expressed their need to receive training to prepare them for teaching ELL students. Effective training for ELLs necessitates professional training for teachers (Nan and Zia, 2010).

Sheltered instruction (SI) includes educational approaches of just good teaching (JGT) and instructional procedures needed for ELLs (Wright, 2010). Hansen-Thomas (2008) advocates that the components of SI are used by teachers in undeliberate manner as they are the same component of JGT. Guarino et al. (2001) tested the dependability of SIOP rubric as a method of evaluating teachers who work with ELLs. A number of studies (e.g., Al-Ansari, 2000; MinayaRowe, 2003; Faltis, 2010) confirm the reliability of using some of SIOP components that are involved in SI strategy. Several studies (e.g., O’Neal et al., 2009; Batt, 2010 and Echevarria et al., 2011) confirmed that SIOP model combine the application of the eight component of the model in addition to SI. In a comparison made between a group of teachers who trained on using SIOP with another group that did not receive the same training, Echevarria et al. (2011) clarified that teachers who applied SIOP inside classrooms managed to be effective teachers. Moreover, Batt (2010), Crawford et al. (2008) and O'Neal et al. (2009) assured that teachers who received training on SIOP model were more responsible, dependable and mindful with their learners' requirements. Furthermore, Whittier and Robinson (2007) proved that SIOP model was effective in teaching new vocabulary.

\section{SIOP Model and Teaching Self-efficacy}

Teacher self-efficacy is the base for effective teaching inside schoolrooms. Teachers who have self-efficacy are trustworthy and able to support students to develop their skills (Pendergast, Garvis and Keogh, 2011). The improvement of teachers' self-efficacy is crucial for making active, devoted and enthusiastic teachers (TschannenMoran and Woolfolk Hoy, 2001). Teacher self-efficacy is stimulated by four sources: mastery experiences; verbal persuasion; vicarious experiences; and emotional arousal. Teaching progression is affected by the four sources. Mastery experiences affect teaching efficacy remarkably as teachers depend on previous teaching experiences which in turn benefit them in the teaching process (Bandura, 1997; Mulholland and Wallace, 2001). Pendergast, Garvis and Keogh (2011) examined teacher education programs and recommended raising teacher self-efficacy through teacher training programs.

Teachers and teacher mentors know the consequence of the association between raising self-efficacy and teaching proficiency (Gorski, Davis, \& Reiter, 2012) and Hemmings, 2015). Using several quantitative rubrics of self-efficacy, Woolfolk Hoy and Burke Spero (2005) determined that there were improvements in preservice teachers' sense of efficacy from the start to the end of teacher training program. However, not all studies report an improvement in selfefficacy due to the effect of teacher training programs. Teacher training program did not add to the improvement of preservice teachers' self-efficacy as assured by Gencer and Cakircglu (2007). Another study by Yilmaz and Cavas (2008) done on 185 preservice teacher who received training on self-efficacy. The researchers used pre-posttest and proved that teacher's self-efficacy did not positively affect due to the training.

A number of studies (e.g., Gibons, 2003; Crawford et al., 2008; Friend et al., 2009 and Batt, 2010) have shown that 
SlOP provide teachers with self-efficacy and provide them with the ability to deal with challenges. It was proven that self-efficacy features positively affected the teaching process. It was confirmed that SIOP model helped lecturers to be active trainers who observe their success through their students' performance and enhance their educational schemes in order to cope with student requirements. Furthermore, the SIOP model provides teachers with academic strategies and evaluation tools that encourage learners to be self-directed and autonomous students (Echevarria, 2008). Additionally, SIOP supports teachers with evaluation measurements that help teachers in the improvement of their performance besides their own professional growth and development (Echevarria, Vogt and Short 2008).

\section{METHODOLOGY}

\section{A. Participants}

A feasible sample of student teachers' from Faculty of Education of Mansoura University was selected and then assigned to a control and an experimental group (11 student teachers' each group). Students' age ranged from nineteen to twenty years. They had been learning English for fourteen years, six at the primary stage, three at the preparatory stage, three at the secondary stage, and two at Faculty of Education. The researchers selected Mansoura University to perform their experiment for some reasons: The instructors of the experimental group were the researchers themselves. The researchers were offered some facilities and support by the university administration.

\section{B. Design}

Adopting the quasi-experimental design, the control and experimental group were pre-tested on their teaching performance and self-efficacy. Then the experimental group received training through SIOP model. On the other hand, the control group received the regular course of the teaching skills. Both groups received the pre-post application of the teaching performance observation checklist and self-efficacy scale to measure improvement in student teachers' teaching skills and self-efficacy.

\section{Instruments}

To achieve the purposes of the study, the researchers prepared two instruments: Teaching performance observation checklist, see Appendix (A) and teaching self-efficacy scale, see Appendix (B). Validity and reliability of the two instruments were established through jury validation and the calculation of internal consistency for the teaching selfefficacy (alpha coefficient $=0.712$ ).

*Appendices are available upon request (prof.qura1@yahoo.com and faten_zahran_7@yahoo.com)

\section{The Treatment}

Program for Developing EFL Student Teachers' Teaching Skills and Self-Efficacy: Based on reviewing related literature and the observation checklist, training program was designed in order to improve student teachers' teaching skills and self-efficacy (Appendix (C)). The program aims at developing the following skills:

1- Developing teaching performance including the eight domains; lesson preparation, building background, comprehensible input, strategies, interaction, practice and application, lesson delivery and review and assessment.

2- Training EFL student teachers on using SIOP model.

3- Developing student teachers' teaching self-efficacy.

\section{E. Materials}

The selected unites from student book of second year of preparatory stage.

\section{F. Aids}

PowerPoint, Worksheet, Mind maps and Grouping.

\section{G. Duration and Content}

The program consisted of two sections that were distributed over twelve sessions. First section was an introduction of SIOP model and practical administration for four lessons (reading, writing, listening and speaking) from student book of second year of preparatory stage using SIOP model. Second section was observation of student teachers inside actual classroom at Shagaret El-Dor prep school. Each session was 90 minutes. The program lasted for one semester. Teaching to the experimental group took place over a period of 12 weeks (February, March and April) during the academic year $2015 / 2016$ from 25/2/2015 till 21/4/2016.

\section{H. Description}

Due to the flexibility and mutual interaction characterizing its components, the program was designed based on SIOP model for the student teachers' group. On the other hand, the control group received regular training. During the second, third, and fourth week of the experiment, the experimental group was introduced to SIOP model. On the fifth, sixth and seventh session student teachers were given practical administration for four lessons (reading, writing, listening and speaking) from student book of second year of preparatory stage using SIOP model.

On the eighth, ninth, tenth, eleventh and twelfth session, the experimental group was observed in actual classroom 
with prep stage students from Shagaret El-Dor prep school. As for the control group, the same lessons had been taught to prep stage students. Each session was 90 minutes. Teaching to the control groups took place over the same period of 12 weeks from 20 /2 / 2015 till 25 /4 /2016. Student teachers' did not receive training on SIOP model.

\section{Evaluation}

In addition to valuing the student teachers' teaching performance, the researchers also focused on evaluating their self-efficacy. In evaluating student teachers' teaching skills, the researchers looked at their ability of mastering the eight components of SIOP model.

\section{RESUlTS AND DISCUSSION}

To examine the first hypothesis, Wilcoxon-Signed Ranks test was used to compare the mean scores of the control and experimental group as shown in table 1 . 
TABLE 1.

WILCOXON-SIGNED RANKS RESULTS OF POST-OBSERVATION CHECKLIST OF THE EXPERIMENTAL AND CONTROL GROUP.

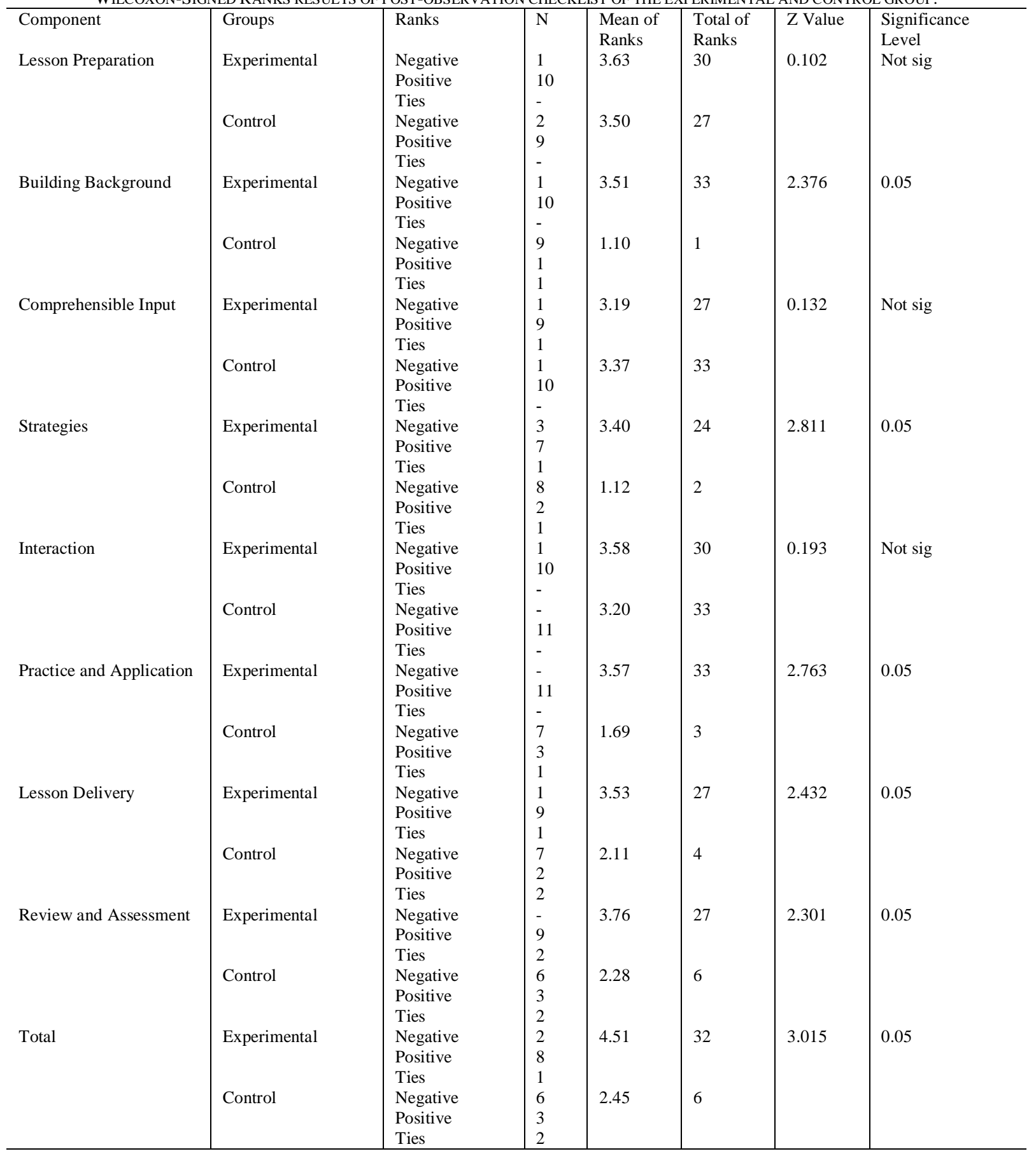

Table 1 indicates that the experimental group outperformed the control group in all components with the exception of lesson preparation, comprehensible input and interaction where the difference was not significant. These results are expected since there is a fixed format for lesson preparation provided by the Egyptian ministry of education. For comprehensible input, this is typical of student teachers whether in experimental or control groups since novice teachers usually speak slowly, repeat more frequently and use active learning skills. As for interaction, active learning, verbal interaction, questioning and cooperative learning are all strategies that both groups study and practice in their methodology. The estimated $\mathrm{Z}$ value for the components; building background, strategies, practice and application, lesson delivery and review and assessment (2.376, 2.811, 2.763, 2.432 and 2.301). These results are in line with those of (Crawford et al., 2008; de Jong, 2005; Friend et al., 2009) in that SIOP model led to improvement in teaching performance. The positive change in experimental group teaching performance could be attributed to using SIOP model that incorporates features of effective teaching.

To test the second hypothesis, Wilcoxon-Signed Ranks test was used to compare the mean scores of the experimental group pre-post observation as shown in table 2 . 
TABLE 2.

WILCOXON-SIGNED RANKS RESULTS OF PRE- AND POST-OBSERVATION CHECKLIST OF THE EXPERIMENTAL GROUP

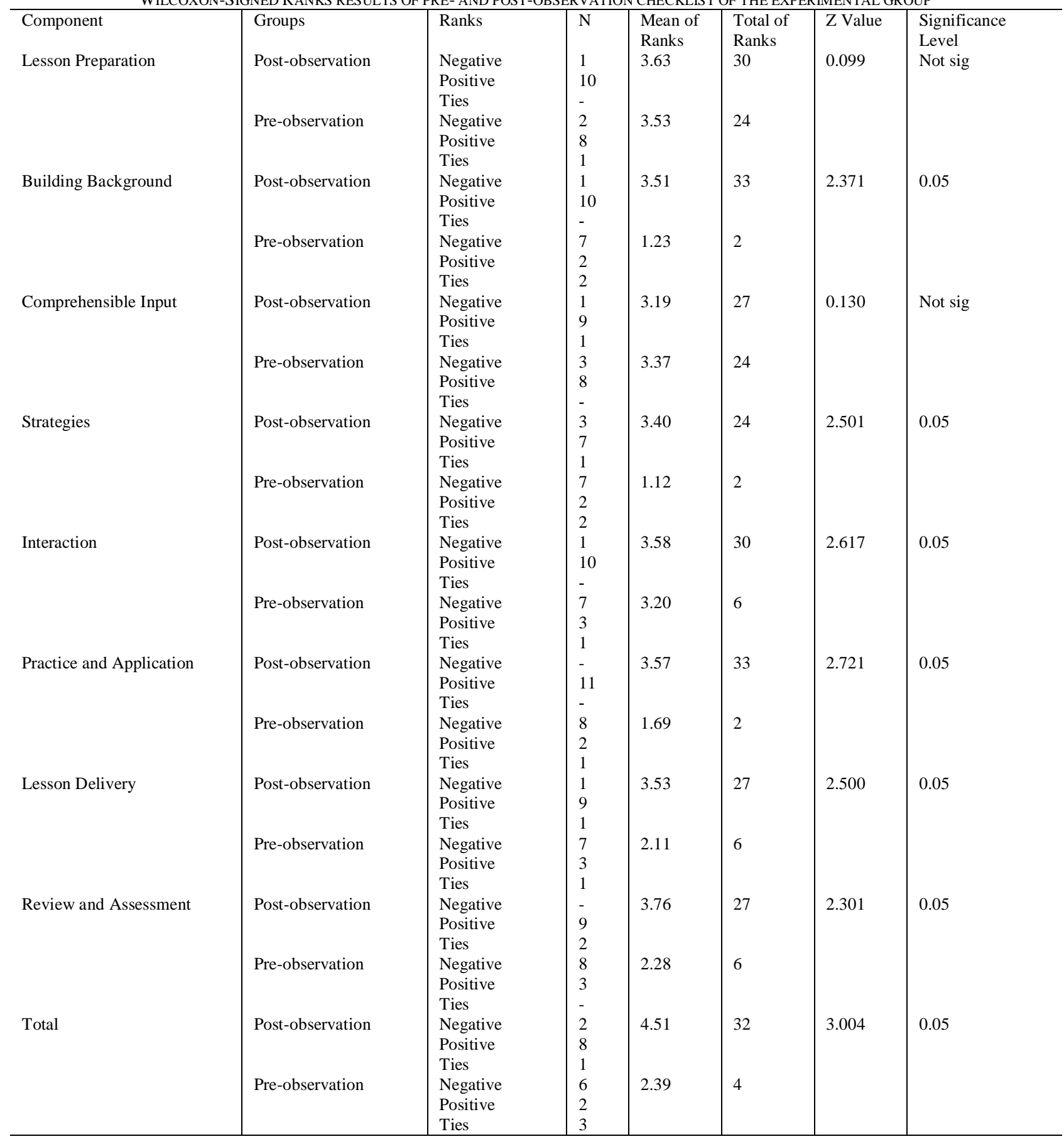

Table 2 indicates that the estimated $\mathrm{Z}$ values for the components; lesson preparation, and comprehensible input (0.099 and 0.130) are not statistically insignificant while $\mathrm{Z}$ values for the components; building background, strategies, interaction, practice and application, lesson delivery and review and assessment $(2.371,2.501,2.617,2.721,2.500$ and 2.301) are statistically insignificant at (0.05) which implies that there is statistically significant difference between the mean score of the experimental group on the teaching skills pre- and post-observation favouring the post-observation scores.

To test the third hypothesis, Wilcoxon-Signed Ranks test was used to compare the mean scores of the control and the experimental group on self-efficacy post scale as shown in table 3. 
TABLE 3.

WILCOXON-SIGNED RANKS RESULTS OF SELF-EFFICACY POST SCALE OF THE EXPERIMENTAL AND CONTROL GROUP

\begin{tabular}{|c|c|c|c|c|c|c|c|}
\hline Self-efficacy Scale & Scale & Ranks & $\mathrm{N}$ & $\begin{array}{l}\text { Mean of } \\
\text { Ranks }\end{array}$ & $\begin{array}{l}\text { Total of } \\
\text { Ranks }\end{array}$ & Z Value & $\begin{array}{l}\text { Significance } \\
\text { Level }\end{array}$ \\
\hline Total of Scale Items & $\begin{array}{l}\text { Experimental } \\
\text { Control }\end{array}$ & $\begin{array}{l}\text { Negative } \\
\text { Positive } \\
\text { Ties } \\
\text { Negative } \\
\text { Positive } \\
\text { Ties }\end{array}$ & $\begin{array}{l}2 \\
8 \\
1 \\
7 \\
4 \\
-\end{array}$ & 4.73 & 32 & 3.107 & 0.05 \\
\hline
\end{tabular}

Table 3 indicates that the estimated $\mathrm{Z}$ value (3.107) is statistically insignificant at (0.05) level. This reveals that the use of SIOP helped increase the teaching efficacy for the experimental group. The preceding results agree with those of (Crawford, 2008; de Jong, 2005; Friend et al., 2009; Batt, 2010 and Echevarria, Short and Vogt, 2010) that S1OP support teachers with high personal efficacy as individuals that are not afraid of a challenge They found that SIOP helped teachers to be effective successful teachers who observe and develop their academic strategies and schemes in accordance with learner requirements.

To examine the fourth hypothesis, Wilcoxon-Signed Ranks test was used to compare the mean scores of the experimental group pre-post self-efficacy scale as shown in table 4.

TABLE 4.

WILCOXON-SIGNED RANKS RESULTS OF SELF-EFFICACY PRE- AND POST-SCALE OF THE EXPERIMENTAL GROUP

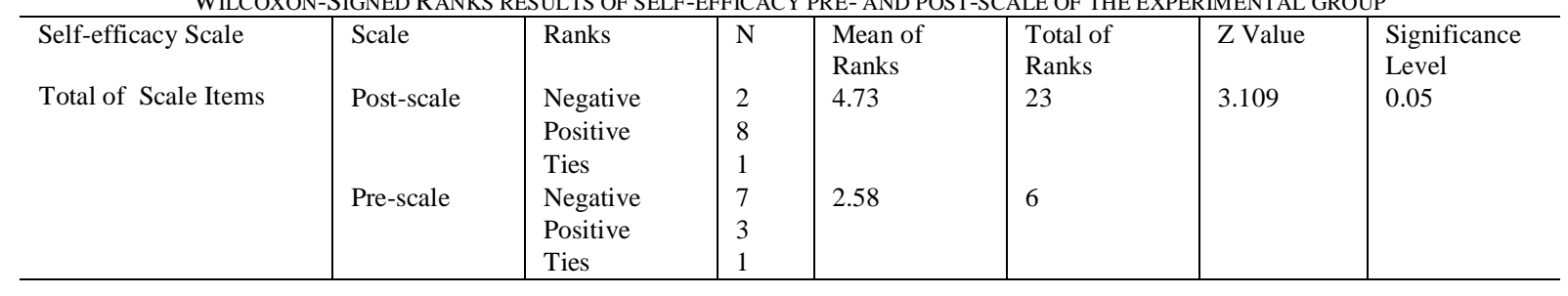

Table 4 indicates that the estimated $\mathrm{Z}$ value (3.109) is statistically insignificant at (0.05) level. This implies that the teaching self-efficacy for the experimental group was enhanced due to the use of SIOP practices.

\section{DisCuSSION OF RESUlts}

The main concern of the study was to investigate the impact of SIOP model on student teachers' teaching skills and self-efficacy. The results of the study show significant differences between the experimental group and the control group that received the regular instruction. These differences came in favour of the experimental group. The control group lacked the important factors that relate to teachers' effectiveness, namely giving feedback, providing instruction, praising students, linking instruction to students' background and using activities for students to apply content and language knowledge in their learning. This result is in line with studies such as (Koura, 2002; Al-Sheikh, 2004; Gohar, 2014). Comparing the student teachers performance of the experimental group at the beginning of the program until its end reveals that there has been a gradual development in their teaching skills and self-efficacy. Their teaching at the beginning of the program focused on mere teaching grammar and new vocabulary to their prep stage students. Most of them even used fragmented techniques. The SIOP training program acted as a guiding framework for student teachers. The sheltered instruction model is remarkable by using of additional resources that enrich the educational material with diagrams, pictures, videos and computer-based material. Improving students understanding of their educational text is the main target of using additional resources. These resources helped student teachers to enrich and develop their teaching skills and self-efficacy.

Before applying the SIOP training program, student teachers viewed teaching skills as dealing with grammar and new vocabulary and viewed assessment as asking questions to solicit students' knowledge. By the end of administering the proposed program, student teachers changed their views of teaching skills seeing it as systematic process that follows a set of logical and rational procedures. The effect of SIOP model on student teachers teaching skills and self-efficacy was profound and significant. SIOP model was very motivating for student teachers and gave them opportunities to make decisions and be creative. O'Neal et al. (2009), Batt, (2010) and Echevarria et al. (2011) supported this result as they indicated that in operational SI class; students communicate and cooperate with each other and with their lecturer. Moreover, students showed a high level of collaboration that resulted in higher level of thinking. Students also learned how to negotiate, convince, discuss and explain their point of view. Students could practice and use the language and academic content through effective discussion and purposeful tasks. The previous results led to the conclusion that using SIOP model was effective in improving student teachers' teaching skills and self-efficacy.

In the light of the results of this study, teacher education programs should incorporate SIOP model into their language arts curriculum. In this way, teachers can become more knowledgeable, experienced, and qualified at teaching. Future research is needed to investigate the impact of S1OP instruction on students' achievement. 


\section{REFERENCES}

[1] Adel,S., Zareian,G., \& Mardekhoda, F. (2015). A Qualitative Study of EFL Learners' and Teachers' Perceptions on Professionalism. International Journal of Education and Research Vol. 3 No. 2 February 2015.

[2] Al-Ansari, S. (2000). Sheltered curricular exposure and unsheltered extra-curricular exposure as factors influencing the development of academic proficiency in ESL. IRAL: International Review of Applied Linguistics in Language Teaching, 38(3/4), 175-186.

[3] Al-Mutawa, N. (2004). Evaluating Competencies f EFL Primary School Teachers in Kuwait. 24 ${ }^{\text {th }}$ CEDELT National Symposium on English Language Teaching, April 20-22.

[4] Al-Sheikh, A. (2004). The knowledge Base of Egyptian Pre-service EFL Teachers' Education Model- Limitation and Aspirations. Journal of Mansoura Faculty of Education, No. 3, May, part 2, 1-55.

[5] Baik, C; \& Greig, J. (2009). Improving the academic outcomes of undergraduate ESL students: The case for discipline based academic skills programs. Higher Education Research and Development, 28(4), 401-416.

[6] Bandura, A. (1997). Self-efficacy: The exercise of control. New York: W.H. Freeman.

[7] Bandura, A. (2006). Adolescent Development from an Agentic Perspective. In F. Pajares \& T. Urdan (Eds.), Self-efficacy beliefs of Adolescents (P P. 1- 44). Connecticut: Information Age Publishing.

[8] Batt, E. (2010). Cognitive coaching: A critical phase in professional development to implement sheltered instruction. Teaching and Teacher Education: An International Journal of Research and Studies, 26(4), 997-1005.

[9] Birjandi, P., \& Bagherkazemi, M. (2010). The relationship between Iranian EFL teachers' critical thinking ability and their professional success. English Language Teaching, 3 (2), 135-145.

[10] Brophy, 1. E. (2004). Motivating learners to learn ( $2^{\text {nd }}$ Ed.). Mahwah, NJ: Lawrence Erlbaum.

[11] Caprara, G.V., Barbaranelli, c., Borgogni, L., \& Steca, P. (2003). Efficacy beliefs as determinants of teachers' job satisfaction. Journal of Educational Psychology, 95, 821-832.

[12] Coulter, T. (2007). Assessing teacher quality and Which Teachers Are most likely to improve student achievement. The progress of education reform journal. Vol. (8), N.4,.24

[13] Crawford, L., Schmeister, M., \& Biggs, A. (2008). Impact of intensive professional development on teachers' use of sheltered instruction with students who are English language learners. Journal of In-service Education, 34(3), 327-342.

[14] Curtin, E. (2005). Teaching practices for ESL students. Multicultural Education, 12(3), 22-29.

[15] De Jong, E. J., \& Harper, C. A. (2005). Preparing Mainstream Teachers for English-Language Learners: Is Being a Good Teacher Good Enough? Teacher Education Quarterly, 32(2), 101-124.

[16] Echevarria, J. D. (2006) School Reform and Standards- Based Education: A Model for English-Language Learners. The Journal of Educational Research,. Vol. 99, No. 4, 200-218.

[17] Echevarria, J. D. (2007). Programs and Practices for Effective Sheltered Content Instruction. San Fransico: Center for Applied Instruction

[18] Echevarria, J. D. (2008). SlOP: Making Content Comprehensible for ELLs. Boston: Pearson.

[19] Echevarria, 1., \& Short, D. (2004). Using multiple perspectives in observations of diverse classrooms: The sheltered instruction observation protocol (SIOP). In H. Waxman, R. Tharp, \& S. Hilberg (Eds.), Observational research in US. Classrooms: New approaches for understanding cultural and linguistic diversity (pp. 21-47). Boston: Cambridge University Press.

[20] Echevarria, J., Vogt, M. E., \& Short, D. (2008). Making content comprehensible for English learners: The SIOP model. New York, NY: Pearson Inc.

[21] Echevarria, J., Richards-Tutor, C., Chinn, V. P., \& Ratleff, P. (2011). Did they get it? The role of fidelity in teaching English learners. Journal of Adolescent \& Adult Literacy, 54(6), 425-434.

[22] Evans, L. (2008). Professionalism, professionality and the development of education professionals. British Journal of Educational Studies, 56 (1), 20-38.

[23] Faltis, C., Arias, M. B., Ramírez-Marín, F. (2010). Identifying relevant competencies for secondary teachers of English learners. Bilingual Research Journal, 33, 307-328.

[24] Friend, J., Most, R., \& McCrary, K. (2009). The impact of a professional development program to improve urban middle-level English language learner achievement. Middle Grades Research Journal, 4 (1), 53-75.

[25] Gencer, A. S., \& Cakiroglu, J. (2007). Turkish preservice science teachers' efficacy beliefs regarding science teaching and their beliefs about classroom management. Teaching and Teacher Education, 23 (5), 664-675.

[26] Giouroukakis, V., Cohan, A., Nenchin, J., \& Honig, A. (2011). A second set of eyes and ears. Journal of Staff Development, 32(3), 60-63.

[27] Gibbons, B. (2003). Supporting elementary science education for English learners: A constructivist evaluation instrument. Journal of Educational Research, 96(6), 371-380.

[28] Gohar, R. (2014). The Effectiveness of a proposed program in electronic assessment-driven instruction on developing EFL teaching skills for student teachers at faculties of education. Unpublished doctoral dissertation, Mansoura University: Faculty of Education.

[29] Gordon, K. W. (2008). Curriculum evaluation of technical vocational training, A case study. University of Nottingham, Unpublished doctoral dissertation.

[30] Gorski, P.E., Davis, S. N., \& Reiter, A. (2012). Self-efficacy and multicultural teacher education in the United States: The factors that influence who feels qualified to be a multicultural teacher educator. Multicultural Perspectives, 14(4), 220-228.

[31] Guarino, A. J., Echevarria, J., Short, D., Schick, J. E., Forbes, S., \& Rueda, R. (2001). The sheltered instruction observation protocol: Reliability and validity assessment. Journal of Research Education, 11(1), 138-140.

[32] Hansen- Thomas, H. (2008). Sheltered instruction: Best practices for ELLs in the mainstream. Kappa Delta Pi Record, 44(4), 165-169.

[33] Hassan, S. (2014). A proposed blended learning program for developing reflective teaching skills of EFL prospective teachers. Unpublished doctoral dissertation, Mansoura University: Faculty of Education. 
[34] Hemmings, B. C. (2015). Strengthening the teaching self-efficacy of early career academics. Issues in Educational Research, 25(1), 1-17.

[35] Koura, A. (2002). Perceived Teaching Performance of Effective Teachers According to Three EFL Groups as Related to Students' Achievement and Attitudes towards Learning EFL. The Specific Role of EFL for the Arab World: The Decade Ahead, in the 22 $2^{\text {nd }}$ CDELT National Symposium on English Language Teaching, CDELT Proceedings Ain Shams University, Cairo, 2003.

[36] Kumaravadivelu, B. (2003). Beyond methods: Macro strategies for language teaching. New Haven: Yale University Press.

[37] Minaya-Rowe, L. (2003). When real-life takes the place of simulation: Transforming teaching and learning through sheltered instruction. Talking Leaves, (7)1. UC Berkeley: Center for Research on Education, Diversity and Excellence. Retrieved January 10, 2016, from http://escholarship.org/uc/item/2vs7p8fq.

[38] Mulholland, 1., \& Wallace, 1. (2001). Teacher induction and elementary science teaching: Enhancing self-efficacy. Teaching and Teacher Education, 17, 243- 261.

[39] Nan, L., \& Zia, H. (2010). Closing the achievement gap: Strategies for ensuring the success of minority students. National Teacher Education Journal, 3(2), 47-59.

[40] O’Neal, D., Ringler, M., \& Lys, D. (2009). Changing teacher attitudes toward instruction of academic language through sustained school-university partnership. International Journal of Educational Leadership Preparation, 4 (4), 1-7.

[41] Pendergast, D; Garvis, S; and Keogh, J (2011) "Pre-Service Student-Teacher Self-efficacy Beliefs: An Insight into the Making of Teachers," Australian Journal of Teacher Education: Vol. 36: Iss. 12, 21-33.

[42] Suwandee, A. (1995). Learners' perceptions of university instructors' effective teaching characteristics. SLLT Journal, 5, 6-22.

[43] Swann, M., McIntyre, D., Pell, T., Hargreaves, L., \& Cunningham, M. (2010). Teachers' conceptions of teacher professionalism in England in 2003 and 2006. British Educational Research Journal, 36 (4), 549-571.

[44] Todd,T., Stinson,T \& Sivakumaran, T. (2011). Strategies For Improving Academic Performance By Non-Native English Speakers In Graduate Programs. Journal of College Teaching \& Learning - December 2011 Volume 8, Number 12.

[45] Tschannen-Moran, M., \& Woolfolk Hoy, AW. (2001). Teacher efficacy: Capturing an elusive construct. Teaching and Teacher Education, 17(7), 783-805.

[46] Tucker, P. D., Stronge, 1. H., \& Gareis, C. R. (2002). Handbook on teacher portfolios for evaluation and professional development. Larchmont, NY: Eye on Education.

[47] Whittier, L., \& Robinson, M. (2007). Teaching evolution to non-English proficient students by using Lego robotics. American Secondary Education, 35(3), 19-28.

[48] Woolfolk Hoy, A., \& Burke Spero, R. (2005). Changes in teacher efficacy during the early years of teaching: A comparison of four measures. Teacher and Teacher Education, 21, 343-356.

[49] Wright, W. (2010). Foundations for teaching English language learners: Research, theory, policy, and practice. Philadelphia, PA: Caslon, Inc.

[50] Yilmaz, H., \& Cavas, P. H. (2008). The effect of the teaching practice on preservice elementary teachers' science teaching efficacy and classroom management beliefs. Eurasia Journal of Mathematics. Science, \& Technology, 4(1), 45-43.

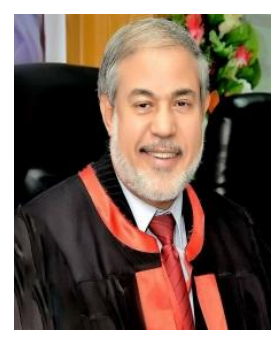

Aly A. Koura is a professor of TEFL in the Department of English at Mansoura University, Egypt. He received his doctoral degree at George Washington University, USA, in 1986. He has published 40 books and research papers in several accredited journals.

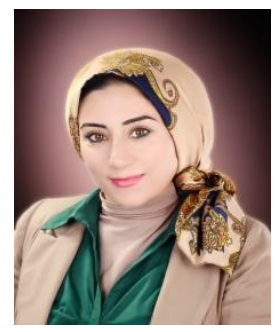

Faten A. Zahran is a lecturer in the Department of English at the Higher Institute of Languages, Mansoura, Egypt. She received her doctoral degree from the Department of Curriculum and Instruction at Cairo University, Egypt, in 2015. Her research interests include ability grouping and individual differences in foreign language learning. 